\title{
Working with Interpreters for Spoken Languages
}

\author{
Dr Qulsom Fazil \\ CPD Editor, Diversity and Equality in Health and Care; Lecturer in Disability Studies and Behavioural Science, Institute of Applied \\ Health Research, College of Medical and Dental Sciences, University of Birmingham, UK
}

\section{Jackie Beavan, former Lecturer in Clinical Communication, College of Medical and Dental Sciences, University of Birmingham (now retired)}

\section{Introduction}

The last UK Census revealed that 8 per cent of people in England or Wales do not speak English (or Welsh) as their main language. Of these 'Non-English-speaking background' (NESB) people, 17 per cent report that they speak English "not well" and 3 per cent that they do not speak it at all. (ONS 2011). After English, the most commonly spoken languages are Polish, Punjabi and Urdu. With the movement of people within the EU and the many people fleeing war, persecution and poverty, the diversity of languages heard in the UK is immense and probably increasing. In London alone, over 300 languages are spoken (Baker \& Eversley 2000). In the United States, the American Community Survey (2011) reports that 22 per cent of the population say they speak English "not well" or "not at all" (Ryan 2013). In some states, 'Hispanic' is recognised as effectively a second national language group. Providing high quality services that meet the language needs of diverse communities in health and social care is clearly a challenge. The aim of this CPD feature is to provide those working in health and social care services with an appreciation of the vital role of professional interpreters and to highlight the skills needed to conduct a consultation with an interpreter present.

\section{At the end of this CPD feature, you should be able to:}

- Understand the reasons for using professional interpreters in health and social care.

- Identify an appropriate interpreter for your patient/ client.

- Conduct an effective consultation with an interpreter present.

\section{What does an Interpreter do?}

Interpreting not only requires an excellent knowledge of both languages but can also requires a good understanding of the relevant subject matter. Being able to facilitate communication between a health professional and a patient/client without the loss of meaning or dilution of context is a specialised skill. It is therefore crucial that an interpreter has a recognised qualification in professional interpreting, ideally in the context of healthcare. NHS England, who have developed a draft set of principles for high quality interpreting and translation services (resource details provided below), state that:

"The use of an inadequately trained (or no) interpreter poses risks for both the patient and the health care provider". They also suggest that using an untrained interpreter may create an even higher risk than having no interpreter at all. They recommend that interpreters working in the NHS and Social Care should be suitably qualified, have the right skills to provide the service, as well as being trained annually in safeguarding. All spoken language interpreters should be registered with the National Register of Public Service Interpreters (NRPSI).

Principles for high quality interpreting and translation services, NHS England. Accessed at:

http://www.england.nhs.uk/commissioning/wp-content/ uploads/sites/12/2015/03/it_principles.pdf

\section{Why do we need interpreters?}

There are many studies that have examined whether interpreters improve the experience of health care for those with limited English proficiency (LEP). A systematic literature review by Karliner et al. (2007) reported that using professional interpreters is associated with a reduction in communication errors, better patient understanding, improved utilisation of health care services, better clinical outcomes and increased patient satisfaction. The review concluded that there is overall improvement in health care for LEP patients when services provided professional interpreters than when they used ad hoc interpreters. Gill et al (2011) found in their study of 41 UK practices that professional interpreters were under-used in relation to the need for them and that family and friends were often used. Practitioners were also found to carry on with a consultation with patients who had little or no English, even when they reported that their own proficiency was low in the patient's language. Similarly, Fazil et al (2015) reported poor levels of language provision in cancer care diagnosis and continuing care and outlined the adverse consequences of this for patients. As well as overall poor health care experience and misunderstandings in communication, there may be difficulties in seeking and receiving informed consent.

The new NHS England draft guidance on interpreting stipulates that a professional registered interpreter should always be offered where needed, and in cases where an individual wishes to use a family member then informed signed consent should be sought from the patient/client independent of that family member. The use of family members is not unusual and it has been argued that there are some advantages, such as familiarity with the patient's problem and the emotional and moral support they may be able to offer the patient (Free et al 2003). However, there are many disadvantages. In complex or sensitive situations where there may be issues around domestic violence, child protection, mental health or sexual matters, communicating through family members may be counterproductive at best and, at worst, dangerous. It should also be remembered that family members are not trained in interpreting and may find it difficult to interpret with accuracy. Children should never be used. 


\section{The Law and Interpreting}

Even though it is not clearly stated in law that interpreting is a legal requirement, the law, including the Human Rights Act 1998 and the Equality Act 2010, requires that organisations and statutory bodies are able to provide services that are accessible and for most organisations good communication is crucial in ensuring accessibility of service provision. In addition, mistakes and misdiagnoses which are a direct result of poor communication can result in legal liability.

\section{Being Prepared}

Being able to work with an interpreter, understanding the role of interpreting, knowing how to access an interpreter and having knowledge of the different types of interpreting available is 'acquired knowledge' - or at least, skills that can be learned. The organisation you work for should ensure that staff have been offered training on using interpreting services. It is your responsibility as a practitioner to seek out such training.

\section{Selecting the right interpreter}

NHS England guidance is clear that interpretation and translation should be free and patients must not be required to pay for interpreting. It is important once you have identified a specific need for an interpreter, that this is recorded on the patient's file, so that others do not have to repeat the process of working out the language spoken and the right interpreter. When assigning an interpreter there are some important points to consider.

- The correct language (and sometimes the exact dialect spoken) must be established. There is often a difference between the dialect of an area and the official language of a country. For example, the official language of Pakistan is Urdu but many people from Pakistan living in the United Kingdom are from an area called Mirpur and speak a dialect which is called Mirpuri or Potwari. Many people of Bangladeshi heritage speak 'Sylhetti', a dialect that is signficantly different from standard 'Bangla', the national language of that country. Similarly, people from China may speak Cantonese or Mandarin or various other languages, so an exact match of interpreter to patient should be sought. If the patient speaks no English at all and is unaccompanied, a Language Identification Card produced by the Refugee Council can be downloaded from the internet to help identify the language they speak.

http://www.refugeecouncil.org.uk/assets/0002/8395/ Language_ID_chart.pdf

- The political and/or religious background of the patient may also be an important consideration. You might need to find an interpreter for someone who has come from a conflict zone and care should be taken to ensure that the interpreter is not from a background that might cause distress, particularly one who might come from the opposite side of a political or religious divide.

- Gender may be a crucial factor in some cases. For example, when questions of an intimate nature may be asked, a female patient may well prefer not to have a male interpreter. Unsurprisingly, use of a child in such cases is fraught with risks!
As the provider of a health or social care service it is your responsibility to ensure that a person is provided with the right interpreter when they book an appointment and that they are informed in advance that an interpreter has been booked for them. For those patients who have a continuing and immediate need to an interpreter, such as those needing end of life care, it is important that if possible the same interpreter is accessed on subsequent occasions.

\section{Prior to the session}

- Allow sufficient time for the appointment. A double appointment slot is usually needed for an interpretermediated session.

- Book a suitable meeting room or try to ensure that the place where you normally see patients/clients is suitable for an interpreter (reasonably quiet and private with enough space for all parties).

- Ensure that seating is arranged appropriately so that you are able to speak directly to the patient/client and that the interpreter is able to sit in a position where they can easily see, maintain eye contact with and speak to both the person they are interpreting for and yourself. There may be situations where it is important to brief the interpreter on background information prior to the meeting, highlighting key issues.

- Ensure that the patient/client is aware that they are being called in for their appointment.

- The Interpreter should not be left alone with the patient/ client either before or after the meeting. Interpretation should be used solely for the purpose of your consultation with the patient or client.

\section{During the session}

- A welcoming and friendly approach to the patient/ client will help reduce stress and improve their ability to communicate. Some people in this situation may well have had very negative experiences with people they perceive as being in authority (even doctors).

- Once everyone is in the room, ensure that the seating arrangements are acceptable and everyone can be heard.

- Give the interpreter the opportunity to introduce themselves and explain their role to all the parties concerned. If there are carers present ensure that it is clear that the interpreter is present to interpret for all those present that need it.

- Ask the interpreter to explain your role and to reassure the patient that all discussions will be kept strictly confidential.

- Remember the interpreter is only there to interpret, he or she is not an advocate and no other role should be imposed on the interpreter.

- Speak directly to the patient/client, and watch their 'body language', in the same way that you would if the interpreter was not present and the client spoke English. 
- Avoid using jargon, slang, abbreviations, and unnecessary medical terminology.

- Speak in short clear sentences and pause after each complete thought is expressed so that the interpreter can interpret the information in small chunks.

- Ask only one question at a time and wait for a response.

- Remember those elements that are so important in all consultations, such as active listening, checking patient's understanding, shared decision-making and expressing empathy.

Signs that things may not be going well in the consultation

- The patient's expression and body language may not match what the interpreter tells you they are saying. For example, if the patient answers that they have no pain but look as if they are, you will need to check why this is.

- If you have asked quite a long question or given a lengthy explanation and the interpreter conveys this using very few words, it would be useful to ask exactly what has been said. The opposite may sometimes occur too, where a simple question or statement is interpreted at length. Of course, there is often a valid explanation for this, for example, there may be no direct word equivalent, so more words are required.

- If the patient or client appears angry, upset or frightened, this should be questioned and could be a sign that the interpreter is inappropriate for this consultation or it could be that your line of questioning has caused distress.

\section{After the session}

If you feel that a debriefing session would be useful with an interpreter at the end of the session, do this after the patient has left. You can use this opportunity to get feedback as to how the meeting went and also to clarify any points.

\section{Key points}

1. Using professional interpreters where required reduces communication errors, increases patient understanding, leads to better use of health services, produces better clinical outcomes and enhances patient satisfaction.

2. Always use a qualified interpreter where a specific need has been identified.

3. Identify clearly the interpreting needs of the patient/ client.

4. Ensure that all involved are clear about the role of the interpreter.

5. Always speak directly to the patient/client during your consultation.

6. Speak in short clear sentences using straightforward language.

7. Check at the end of the session that the patient/client has understood and if there are any questions

8. Debrief with the interpreter if needed.

\section{Resources}

New NHS draft guidance:

Principles for high quality interpreting and translation services

http://www.england.nhs.uk/commissioning/wp-content/ uploads/sites/12/2015/03/it_principles.pdf

The chapter below is in a training manual which contains some very useful material and information and scenarios to work through.

Beavan, J and Kai J (2005) Language and communication training session. In Kai J (eds) PROCEED: Professionals responding to ethnic diversity and cancer. The University of Nottingham and Cancer Research UK, pp 52-79.

Language Identification Card http://www.refugeecouncil.org. uk/assets/0002/8395/Language_ID_chart.pdf

\section{REFERENCES}

Baker P \& Eversley J (2000) Multilingual capital: The language of London's schoolchildren and their relevance to economic, social and educational policies. London: Battlebridge publications.

Equality Act (2010) HMSO. Available at: www.legislation.gov. uk/upga/2010/15/contents. (Accessed 02/09/2015).

Fazil Q, Aujla N, Hale C, Kai J (2015) Unequal treatment: Health care experiences and needs of patients with cancer from minority ethnic communities. Diversity \& Equality in Health \& Care 12,3 (Free C, Green J, Bhavnani V, Newman A. 2000 'Bilingual young people's experiences of interpreting in primary care: a qualitative study'. British Journal of General Practice. 53; 530-535.

Gill PS, Beavan J, Calvert M, Freemantle N (2011) The Unmet Need for Interpreting Provision in UK Primary Care. Vol 6 , Issue 6, e20837.

Human Rights Act 1998. Available at www.legislation.gov.uk/ ukpga/42/contents. (Accessed 02/09/2015.

Karliner LS, Jacobs EA, Chen AH, Mutha, S (2007) Do Professional Interpreters Improve Clinical Care for Patients with Limited English Proficiency? A Systematic Review of the Literature. Health Services Research 42:2.

ONS Statistical bulletin: 2011 Census: Quick statistics for England and Wales. March 2011.

Ryan C (2013) Language Use in the United States 2011. American Community Survey Reports. ACS-22.

\section{Previously in this Journal}

There have been many articles of relevance in previous issues of Diversity - including many smaller items in the Knowledgeshare feature, and the Practitioner's Blog notably:

Dawood M 2010 'Empathy speaks all languages' Diversity \& Equality in Health \& Care 7,1 :65-66

Martin W, Dawood M 2011 'Are we misinterpreting our patients' needs?' Diversity \& Equality in Health \& Care 8,3 :189-190 
Dawood M, O'Sullivan S 2012 'Actions speak louder than words' Diversity \& Equality in Health \& Care 9,1 :73-74

See also

Eckhardt R, Mott S, Sharon A 2006 'Culture and communication: identifying and overcoming the barriers in caring fort nonEnglish-speaking German patients' Diversity in Health \& Social Care 3,1 :19-25

Irshad T, Worth A, Sheikh A 2007 'Are translation and interpretation services a necessity or a luxury' Diversity in Health \& Social Care 4,2 :87-90

Novak-Zezula S, Schulze B, Karl-Trummer U, Krajic K, Pelikan JM 2005 'Improving interpreting in clinical communication: models of feasible practice from the European project 'Migrant-friendly Hospitals' Diversity in Health \& Social Care 2,3 :223-232

Puebla-Fortier J 2008 'Cultural \& linguistic competence: a global issue' Diversity in Health \& Social Care 5,2 :87-88

Ramos R, Davis JL, Antolino P, Sanz M, Grant CG, Green BL 2014 'Language and communication services: a cancer centre perspective' Diversity \& Equality in Health \& Care $11,1: 71-80$ 